The submitted manuscript has boen autioned by a cuntractor of the U.S. Govemment under contract DE-AC05-84OR21400. Accordingly, the U.S. Government retains nonerclurive the publict form of this contribution, or allow others to do so, for U.S. Government purposes."

\title{
MICROWAVE SINTERING OF ZIRCONIA-TOUGHENED ALUMINA COMPOSITES*
}

DE91 007185

\author{
H. D. Kimrey, J. O. Kiggans, M. A. Janney, and R. L. Beatty \\ Oak Ridge National Laboratory \\ Oak Ridge, Tennessee
}

\section{INTRODUCTION}

Microwave sintering possesses unique attributes and has the potential to be developed as a new technique for controlling microstructure to improve the properties of advanced ceramics. ${ }^{1-6}$ Because microwave radiation penetrates most ceramics, uniform volumetric heating is possible. Thermal gradients, which are produced during conventional sintering because of conductive and radiative heat transfer to and within the part, can be minimized. By eliminating temperature gradients, it is possible to reduce internal stresses, which contribute to cracking of parts during sintering, and to create a more uniform microstructure, which may lead to improved mechanical properties and reliability. With uniform, volumetric temperatures, the generation of nonuniform particle/grain growth due to temperature gradients and associated sintering gradients can be regulated.

Recent investigations rave identified additional benefits to microwave sintering. Using $28-\mathrm{GHz}$ radiation, it was demonstrated that alumina could be densified at $300-400^{\circ} \mathrm{C}$ below temperatures used in conventional processing and that a uniform, fine-grained microstructure could be obtained.1-3 with the advent of lowertemperature processing, it is possible to reduce grain growth, vaporization, and interactions between phases, which are often significant in the fabrication of advanced ceramics.

\footnotetext{
*Research sponsored by the U.S. Department of Energy Assistant Secretary of Conservation and Renewable Energy, Office of Industrial Technologies, Advanced Industrial Materials Program under contract DE-AC05-840R21400 with Martin Marietta Energy Systems, Inc.
}

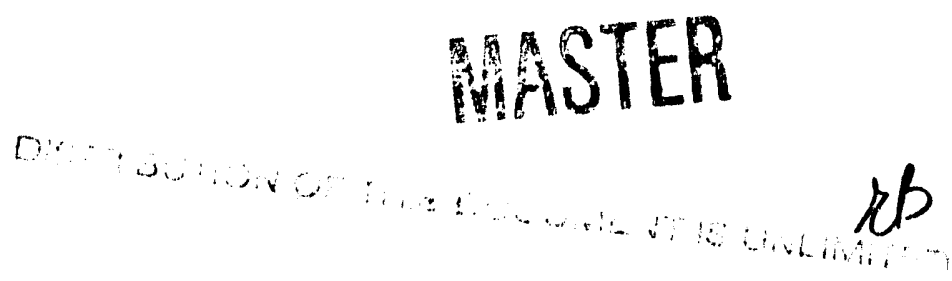




\section{BACKGROUND}

One class of ceramics, in which microstructural control in conjunction with microwave processing is expected to yield improved properties, is transformation-toughened ceramics. The retention of the tetragonal zirconia phase $\left(\mathrm{t}-\mathrm{ZrO}_{2}\right)$ has previously been shown to control the mechanical properties of composites that contain dispersed $\mathrm{ZrO}_{2}$ particles. ${ }^{7-9}$ The amount of $\mathrm{t}-\mathrm{ZrO}_{2}$ retained in the body and the microstructure of the composite significantly affect mechanical properties. Limitations of currently produced zirconia-toughened alumina are related to (1) variations in the composition of the stabilizing additive and (2) the location, grain size, and morphology of the dispersed tetragonal zirconia second phase. For the greatest toughening effects, the tetragonal $\mathrm{ZrO}_{2}$ phase particles must be transformed at a relatively low applied tensile stress, and all particles must transform for similar conditions. This requires that the solute content in the body be uniform and optimized, that the $\mathrm{ZrO}_{2}$ particles have a uniform desired size, and that the shape of the particles be similar (i.e., polyhedral particles transform more easily than do spherical ones). Improvements in the fracture toughness of alumina strengthenod with yttria-partially-stabilized zirconia, for example, occur over a very narrow range from $\sim 1.5$ to $2.5 \mathrm{~mol} \% \mathrm{Y}_{2} \mathrm{O}_{3}$ in the $\mathrm{ZrO}_{2}$. The high sintering temperature of $\sim 1600^{\circ} \mathrm{C}$ required by conventional heating processes often leads to rapid diffusion and variation in the stabilizer content of the zirconia phase from grain to grain. Compositional variations lead directly to decreases and variations in the strength and toughness of the composite. In addition, there is also a critical size of the zirconia-dispersed phase, above which the zirconia particles transform to the monoclinic structure. Particles that are already transformed limit the magnitude of the mechanical properties that can be achieved. Microwave sintering, which produces uniform temperatures and more rapid densification, is expected to produce the degree of control of the densification and nicrostructural development required to produce composites with optimum toughness. Microwave sintering is expected to produce a finer grain size in the matrix alumina phase as well as a finer, more uniform size of the zirconia particles in the matrix. These features will contribute to improved strength, fracture toughness, and mechanical reliability in the composite. Improved mechanical properties and reliability would make zirconia-toughened alumina an attractive material for use in fuel metering systems, turbine 
housings, and applications requiring thermal shock resistance better than that of alumina.

\section{MATERIALS AND METHODS}

Ceramic Materials and Processing

Materials in the $\mathrm{ZrO}_{2} / \mathrm{Al}_{2} \mathrm{O}_{3}$ system containing $10-70$ wt $\% \mathrm{ZrO}_{2}$ were chosen for this study. Alumina (Sumitomo AKP 50) and zirconia (Tosoh TZ-2Y) powders were dispersed together in isopropanol in $400-\mathrm{g}$ batches. The slurry was sonicated for $10 \mathrm{~min}$ and then stirred dry under forced air at $50^{\circ} \mathrm{C}$ on a hot plate. The dried cake was broken up and screened to $-40+100$ mesh. The screened powder was then isopressed in 50- to $100-\mathrm{g}$ coffee cup molds to $30 \mathrm{kpsi}$. Green densities were uniformly close to $55 \%$ of theoretical.

\section{Eurnacing}

The comparative study was performed in a CM Corp. tube furnace and two custom-built microwave furnaces. Samples for conventional sintering were loaded into a 5 -cm-diam alumina tube on alumina boats (both Coors AD998). Temperature was measured in the tube furnace using a type $S$ thermocouple less than $0.5 \mathrm{~cm}$ away from the sample.

The 2.45-GHz microwave furnace was an untuned cavity, $45.7 \mathrm{~cm}$ in diameter and $61 \mathrm{~cm}$ long, powered by a $2.3 \cdot \mathrm{kW}$ Genesys microwave source. Figure 1 is a photograinh of the furnace. Figure 2 is a sequence of photographs showing the casketing for a ZTA sample for processing in the $2.45-\mathrm{GHz}$ cavity. The sample is surrounded by alumina and/or zirconia bulk fibers (Zircar) inside an alumina fiberboard container. Also in the container are five rods of alpha $\mathrm{SiC}, 0.5 \mathrm{~cm}$ in diameter by $10 \mathrm{~cm}$ long, equally spaced on the inside diameter of the container. Temperatures were measured with a type C thermocouple with a combination boron nitride sheath over a molybdenum sheath inserted approximately $1 \mathrm{~cm}$ into the center of the sample.

The 28-GHz microwave furnace was aiso an untuned cavity, $76.2 \mathrm{~cm}$ in diameter and $101.6 \mathrm{~cm}$ long, powered by a 200-kW Varian microwave source. Figure 3 is a photograph of the furnace. The sample was surrounded by bulk fiber as at the low frequency but was held in a boron nitride container as shown in Fig. 4. Temperature was measured in the same way as at $2.45 \mathrm{GHz}$ but without the boron 
nitride sheath. The atmosphere was flowing $\mathrm{N}_{2}$ in all cases. Samples were heated to $1 ? 70-1550^{\circ} \mathrm{C}$ for one hour at heating rates of $5-20^{\circ} \mathrm{C} / \mathrm{min}$.

\section{Analysis}

Samples were measured for density using the Archirnedes technique in 200-proof ethanol. X-ray analysis was performed to determine the phase composition of the zirconia particles. Samples were analyzed in all cases on as fired surfaces. Scanning electron microscopy (SEM) was performed on selected fracture surfaces of samples to determine grain size, texture, homogeny, etc., with a Hitachi S800 electron microscope with backscatter detector attachment for $z$-number contrast.

\section{RESULTS AND DISCUSSION}

The temperature dependence of the densification rate for $\mathrm{Al}_{2} \mathrm{O}_{3}+$ 10,20 , and $30 \mathrm{wt} \% \mathrm{ZrO}_{2}(+2 \mathrm{~mol} \% \mathrm{Y})$ is shown graphically in Fig. 5 for the three furnaces. The most striking feature of this graph is the dramatic reduction in sintering temperature by firing at $28 \mathrm{GHz}$. At temperatures between 1000 and $1100^{\circ} \mathrm{C}$, more than $98 \%$ of theoretical density is achieved. A temperature of $1525^{\circ} \mathrm{C}$ was required for complete densification in the conventional furnace. Another interesting feature of the figure is the apparent reduction in firing temperature required for increasing concentrations of $\mathrm{ZrO}_{2}$ in $\mathrm{Al}_{2} \mathrm{O}_{3}$ in the $2.45-\mathrm{GHz}$ furnace. This observation led to an additional study at $2.45 \mathrm{GHz}$ using up to $70 \mathrm{wt} \% \mathrm{ZrO}_{2}$ in $\mathrm{Al}_{2} \mathrm{O}_{3}$. As shown in Fig. 6, the effect of increasing $\mathrm{ZrO}_{2}$ content past $30 \mathrm{wt} \%$ was nagligible. At $1200^{\circ} \mathrm{C}$ sintering is better with increasing zirconia content. The slope of the sintering curves with respect to temperature, however, decreases with zirconia content above $1200^{\circ} \mathrm{C}$ with the terminal density dropping slightly. These results are perhaps a bit misleading because of the use of the $\mathrm{SiC}$ rods. It was necessary to use the lossy rods at $2.45 \mathrm{GHz}$ because of the electric field nonuniformity in the small cavity. The SiC lowers the $Q$ of the cavity and thereby makes the fields more uniform. The SiC rods also provide combination heating for the sample so that in effect conventional heating takes place at low temperatures. Figure 7 shows plots of typical runs with and without the rods. Initially, the rods heat and are the main absorbers. At higher temperatures the sample begins to couple and absorb power. In the lower plot, for a run, without the rods, a much more pronounced 
effect on the power is observed in that no SiC rods mask the sample response. Without the rods the electric field is much stronger than with the rods. However, the nonuniformity of the field in the former case precludes a more detailed investigation in this small a cavity. The more uniform fields in the $28-\mathrm{GHz}$ cavity do not require the use of the moderating rods for crack-free samples. Figure 8 demonstrates that a strong dielectric relaxation occurs.

Selected samples of high density were selected for $x$-ray analysis. None of the samples, either conventional or microwave, showed $\mathrm{m}-\mathrm{ZrO}_{2}$ of greater than $5 \%$. Figure 9 is a relative comparison using SEM analysis of conventional and microwave-fired samples. A marked difference in grain size is apparent; the microwave case is much finer. Interestingly, there was little difference in the microstructure between $2.45-\mathrm{GHz}$ and $28-\mathrm{GHz}$ firings. From the fracture surface it is estimated that the grain size is approximately $0.5 \mu \mathrm{m}$ for the microwave case and about a $1 \mu \mathrm{m}$ for the conventional case. Generally, the zirconia grains were finer and more discrete in placement within the microstructure for the microwave-fired samples. The samples showed evidence of poor mixing. Where the zirconia phase was lacking, the alumina phase grain size grew to several micrometers.

\section{SUMMARY AND CONCLUSIONS}

The feasibility of firing zirconia-alumina composites has been demonstrated. Techniques have been developed whereby virtually any composition of ZTA can be fired in 2.45- and 28-GHz microwave fields. Comparing data from conventional and microwave firing shows that the sintering temperature can be as much as $500^{\circ} \mathrm{C}$ lower for the microwave case. A reduction in sintering temperature, as suspected, appears to result in a significant decrease in the grain size in the microstructure. Apparently, the path of microstructural change is altered so that densification can proceed with little coarsening as an interfering mechanism. The microwave effect appears to be a function of frequency. Our results give some indication of why the microwave effect was not seen earlier at $2.45 \mathrm{GHz}$. Technological problems associated with producing uniform fields interfere and in this case mask the microwave effect. With larger cavities and perhaps more clever insulation schemes, it may be possible to reproduce the results at $2.45 \mathrm{GHz}$ that are seemingly so easily achieved at higher frequency. 


\section{REFERENCES}

1. H. D. Kimrey, M. A. Janney, and P. F. Becher, "Techniques for Ceramic Sintering Using Microwave Energy," Conference Digest, $12^{\text {th }}$ International Conf. on Infrared and Millimeter Waves, Orlando, FL, December 1987.

2. M. A. Janney and H. D. Kimrey, "Microwave Sintering of Alumina at $28 \mathrm{GHz}, "$ Ceramic Powder Science, II, pp. 919-924, G. L. Messing, E.R. Fuller, and H. Hausner, eds., Am. Ceramic Soc., Westerville, OH, 1988.

3. M. A. Janney and H. D. Kimrey, "Microstructure Evolution in Microwave Sintered Alumina," to be published in Advances in Sintering, Am. Ceramic Soc., Fall 1989.

4. Y. L. Tian, D. L. Johnson, and M. E. Brodwin, "Ultrafine Microstructure of $\mathrm{Al}_{2} \mathrm{O}_{3}$ Produced by Microwave Sintering," Ceramic Powder Science, II, pp. 925-32, G.L. Messing, E.R. Fuller, and $\mathrm{H}$. Hausner, eds., Am. Ceramic Soc., Westerville, $\mathrm{OH}$, 1988.

5. C. E. Holcombe, "Microwave Sintering of Non-Oxide Ceramics," presented at the 91st Annual Meeting of the American Ceramic Society, Indianapolis, IN, April 1989.

6. M. A. Schmidt, M. A. Janney, and J. R. Mayotte, "SEM Image Analysis of Grain Growth in Microwave-Annealed Alumina," Microstructural Science, Vol. 18, Proc. 22nd IMS Meeting, Charlotte NC, July 1989, IMS and ASM International, in press.

7. R. C. Garvie and R. H. J. Hannink, "Ceramic Steel?," Nature (London), 258 [5337] 703-704 (1975).

8. N. Claussen, "Fracture Toughness of $\mathrm{Al}_{2} \mathrm{O}_{3}$ with an Unstabilized $\mathrm{ZrO}_{2}$ Dispersed Phase," J. Am. Ceram. Soc. 59 [1-2] 49-51 (1976).

9. D. L. Porter and A. H. Heuer, "Mechanisms of Toughening Partially Stabilized Zirconia (PSZ)," J. Am. Ceram. Soc. 60 [3-4] 183-84 (1977). 


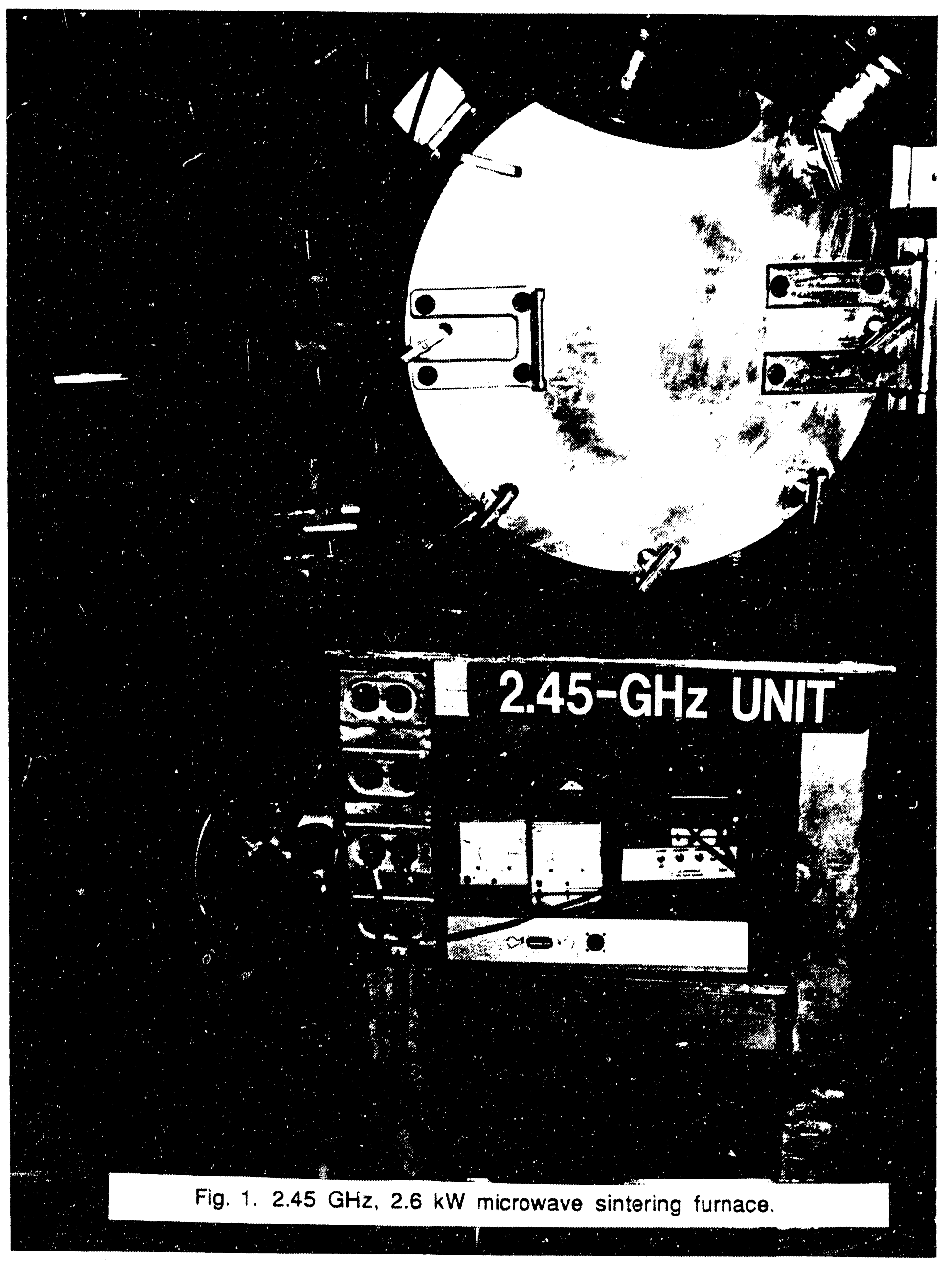

\section{Fig. 1. $2.45 \mathrm{GHz}, 2.6 \mathrm{~kW}$ microwave sintering furnace}



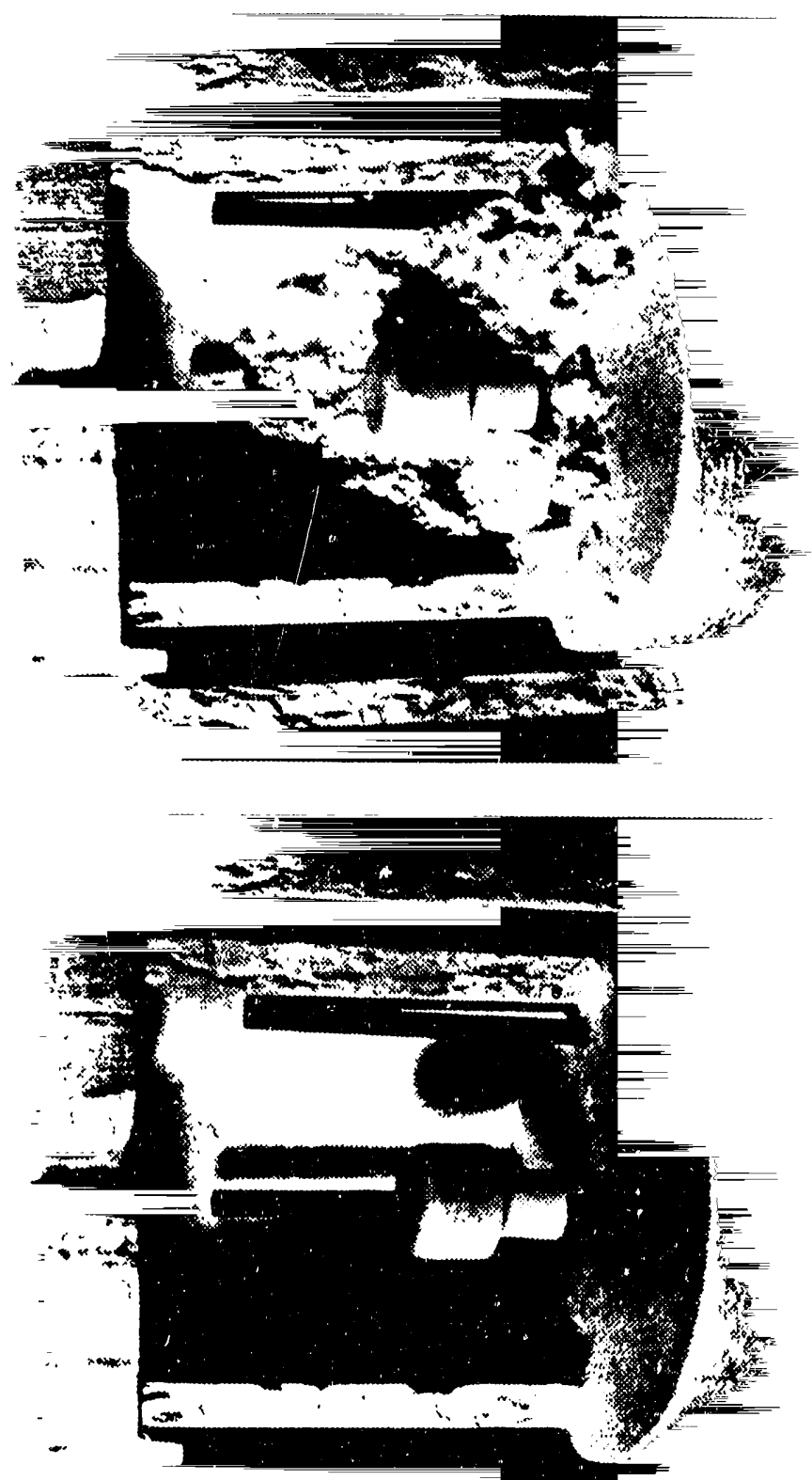

$-x-1+2$

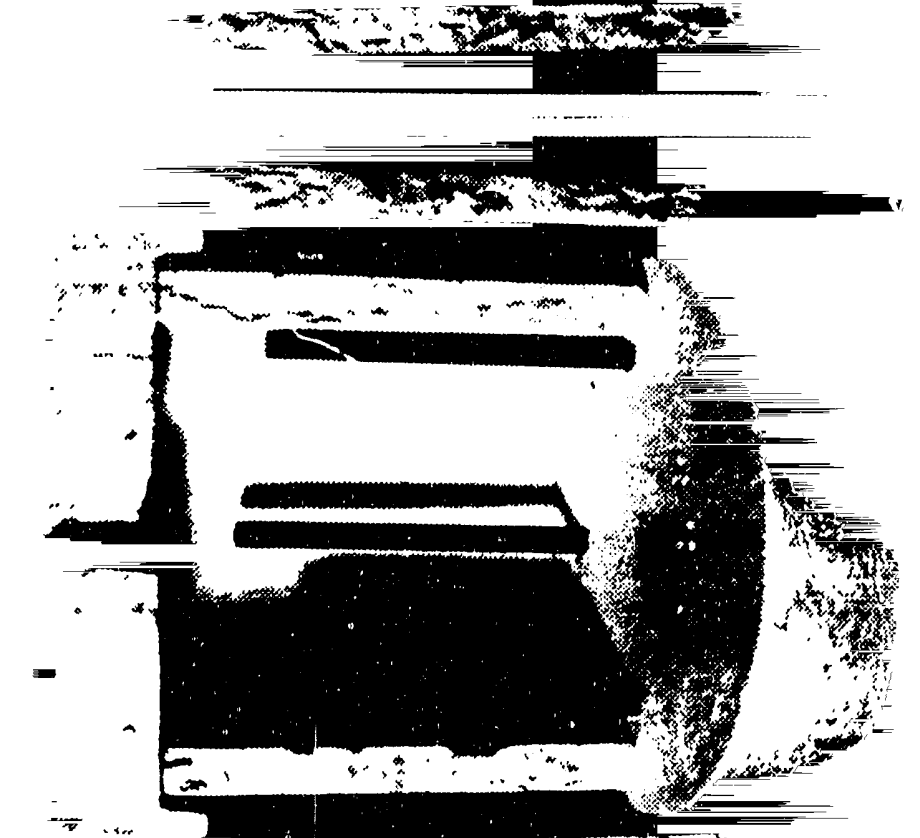

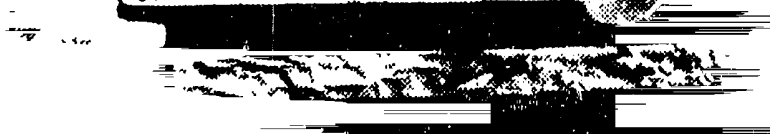




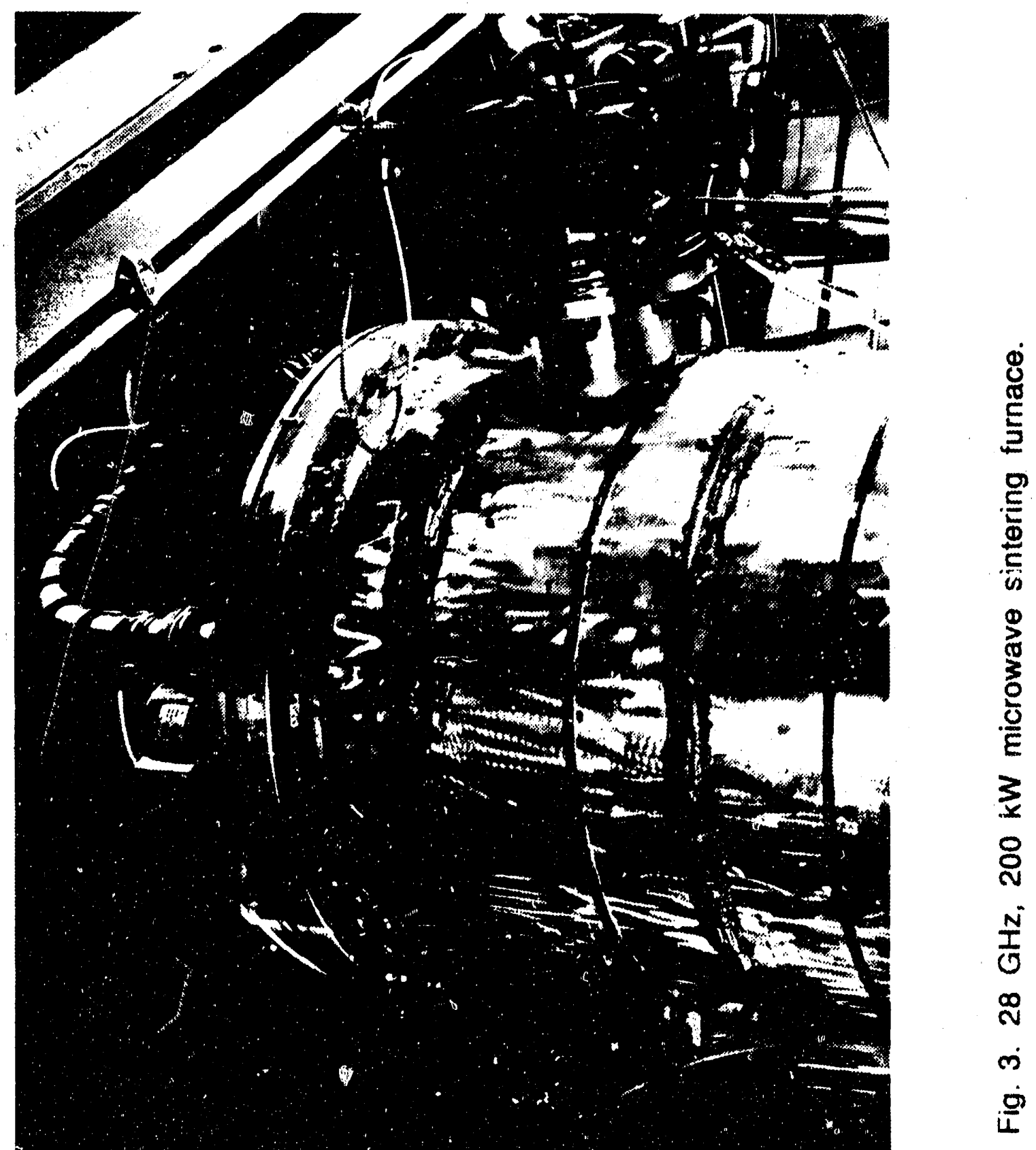




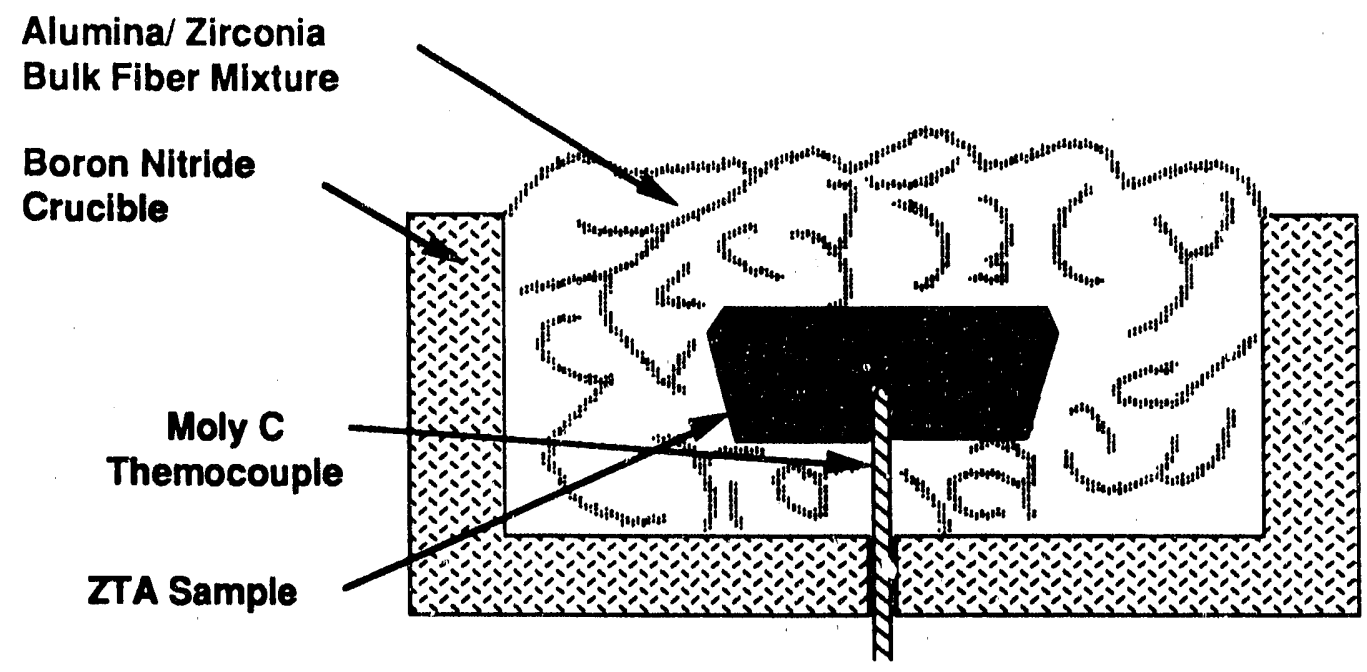

Fig. 4. Casket used in sintering ZTA at $28 \mathrm{GHz}$. 


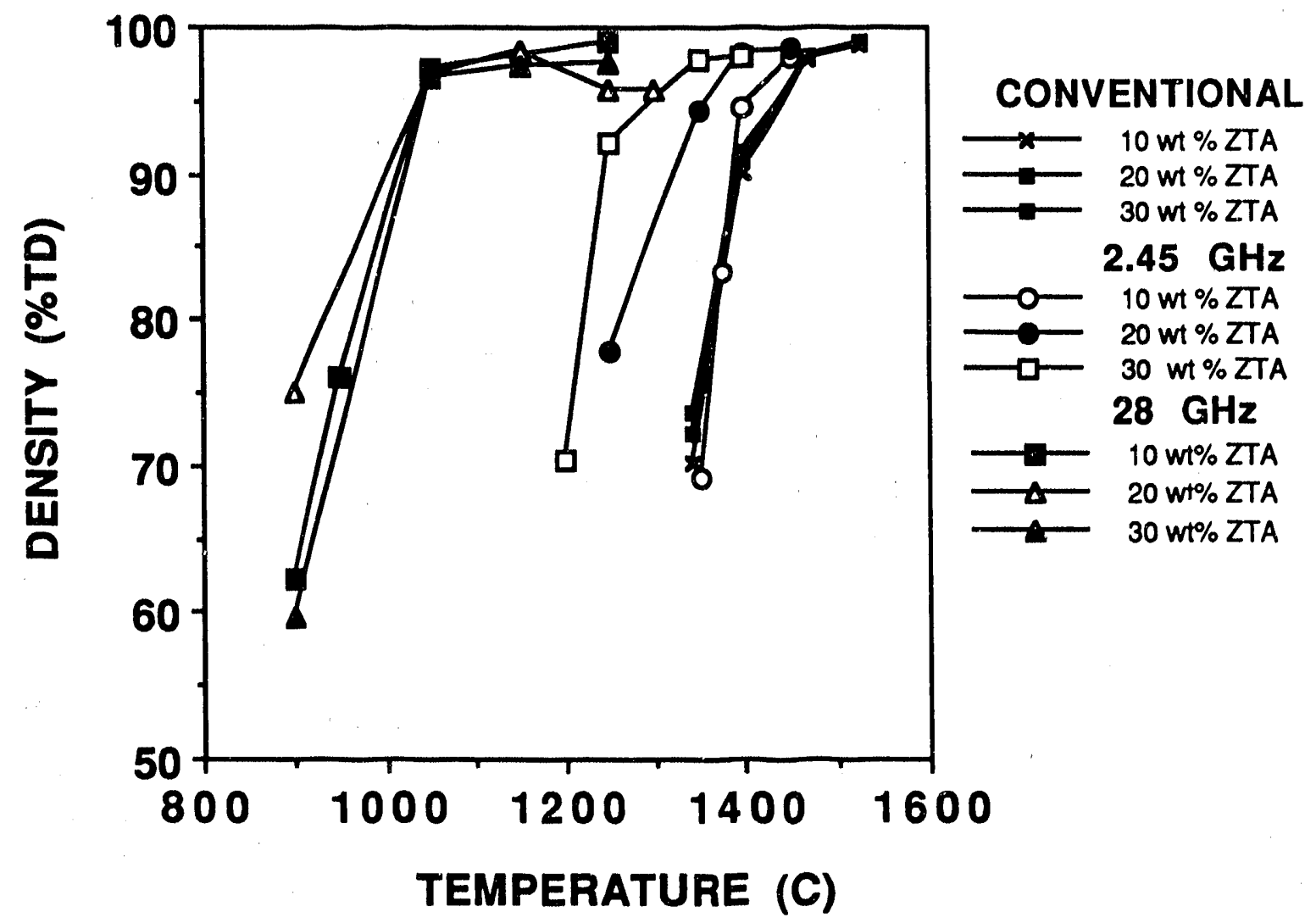

Fig. 5. Densification behavior of zirconia toughened alumina sintered at $2.45 \mathrm{GHz}, 28 \mathrm{GHz}$, and conventional furnaces. 


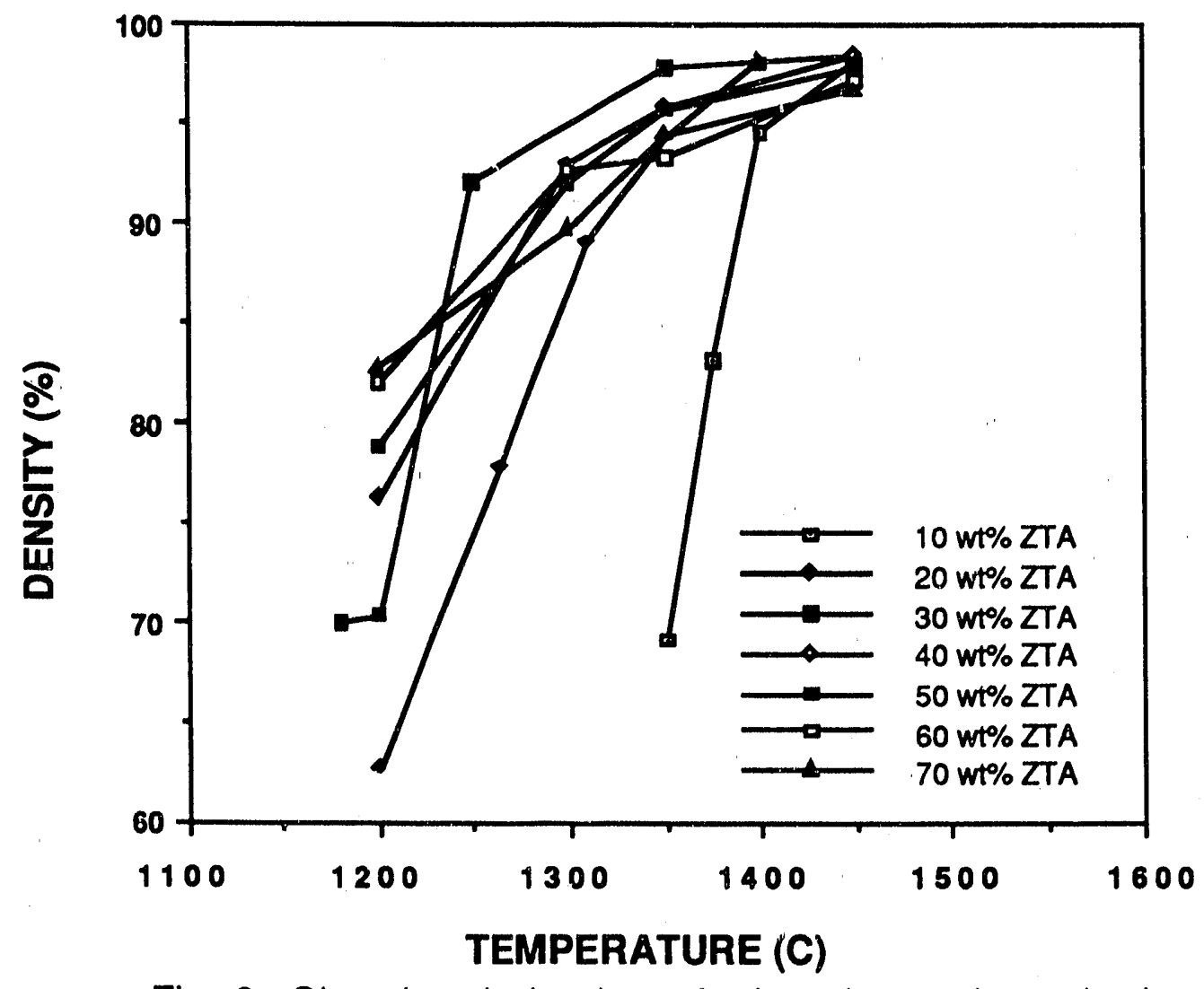

Fig. 6. Sintering behavior of zirconia-toughened alumina as a function of composition at $2.45 \mathrm{GHz}$ with mixedmode heating. 

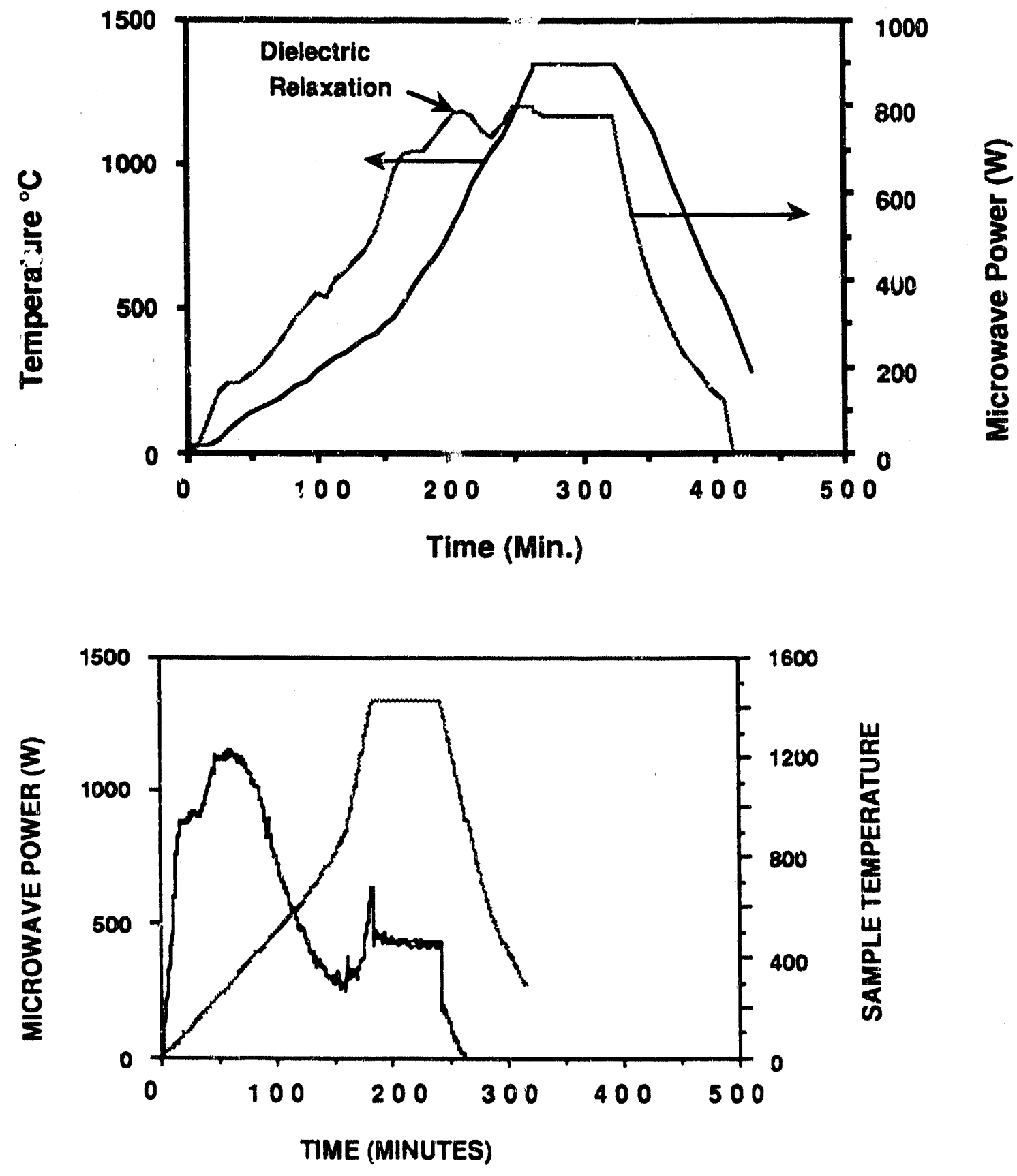

Fig. 7 Dielectric relaxation is more pronounced without (lower) than with (upper) the SiC rods at $2.45 \mathrm{GHz}$. 


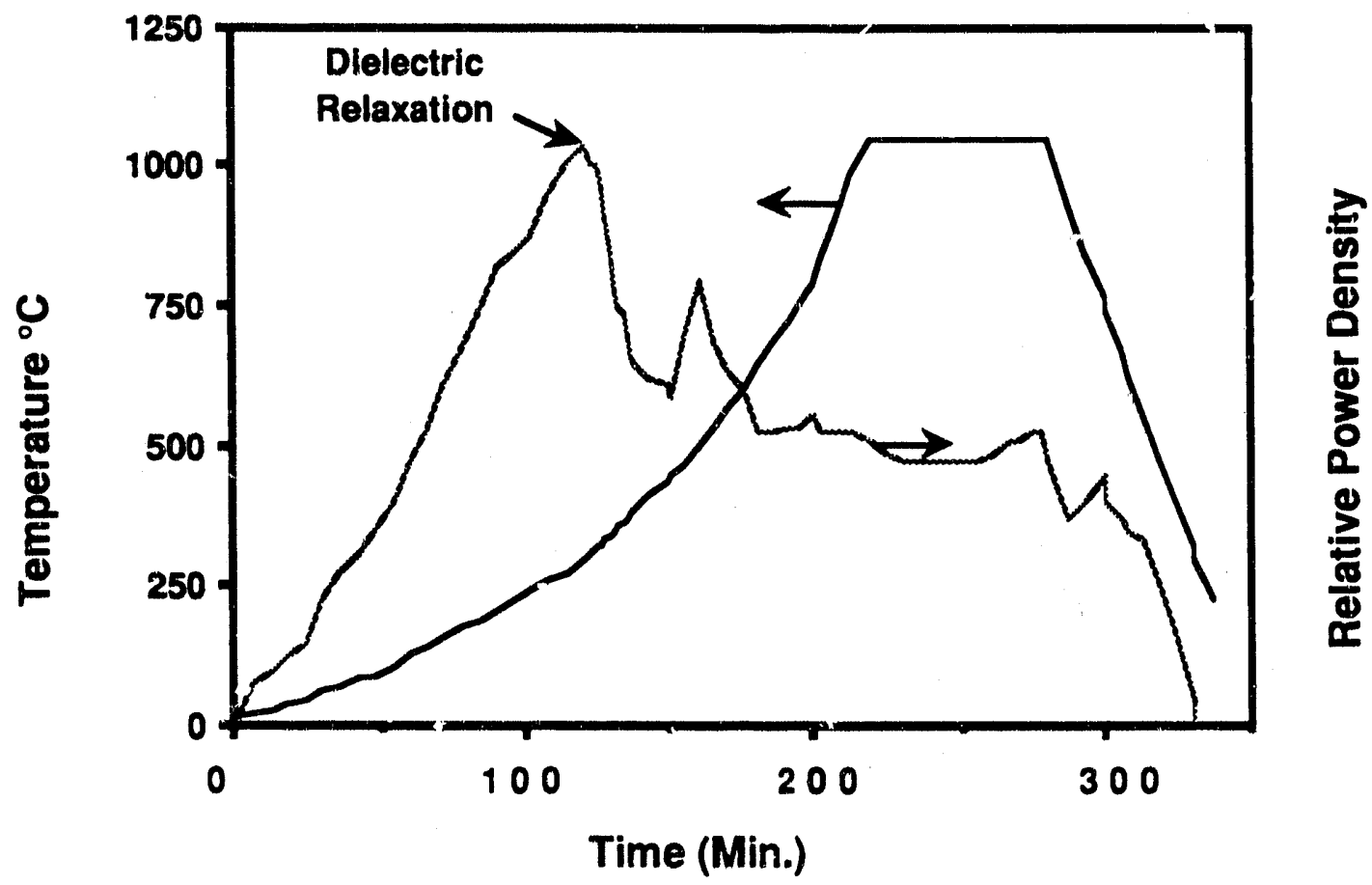

Fig. 8 Dielectric relaxation demonstrated at $28 \mathrm{GHz}$ 

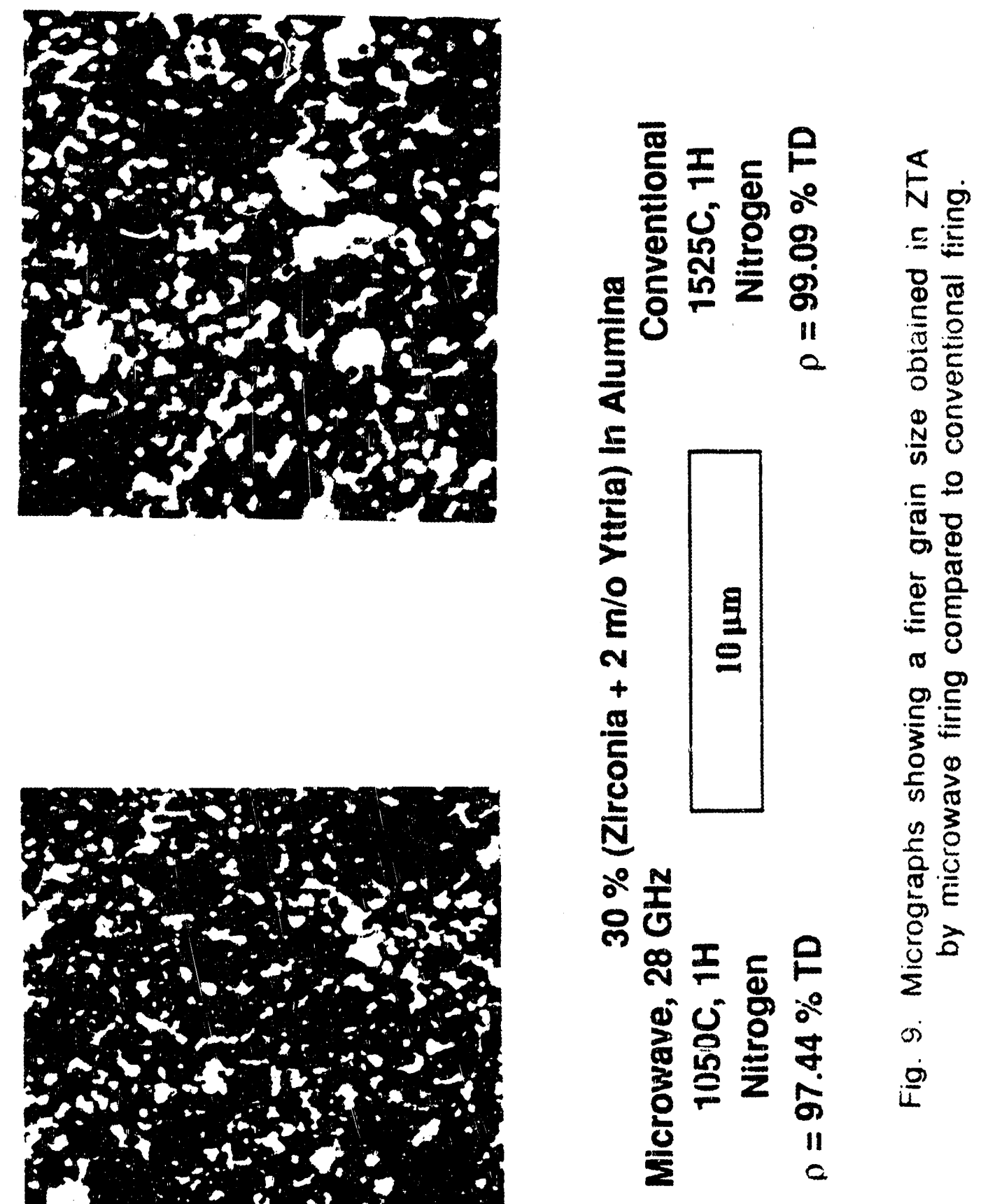

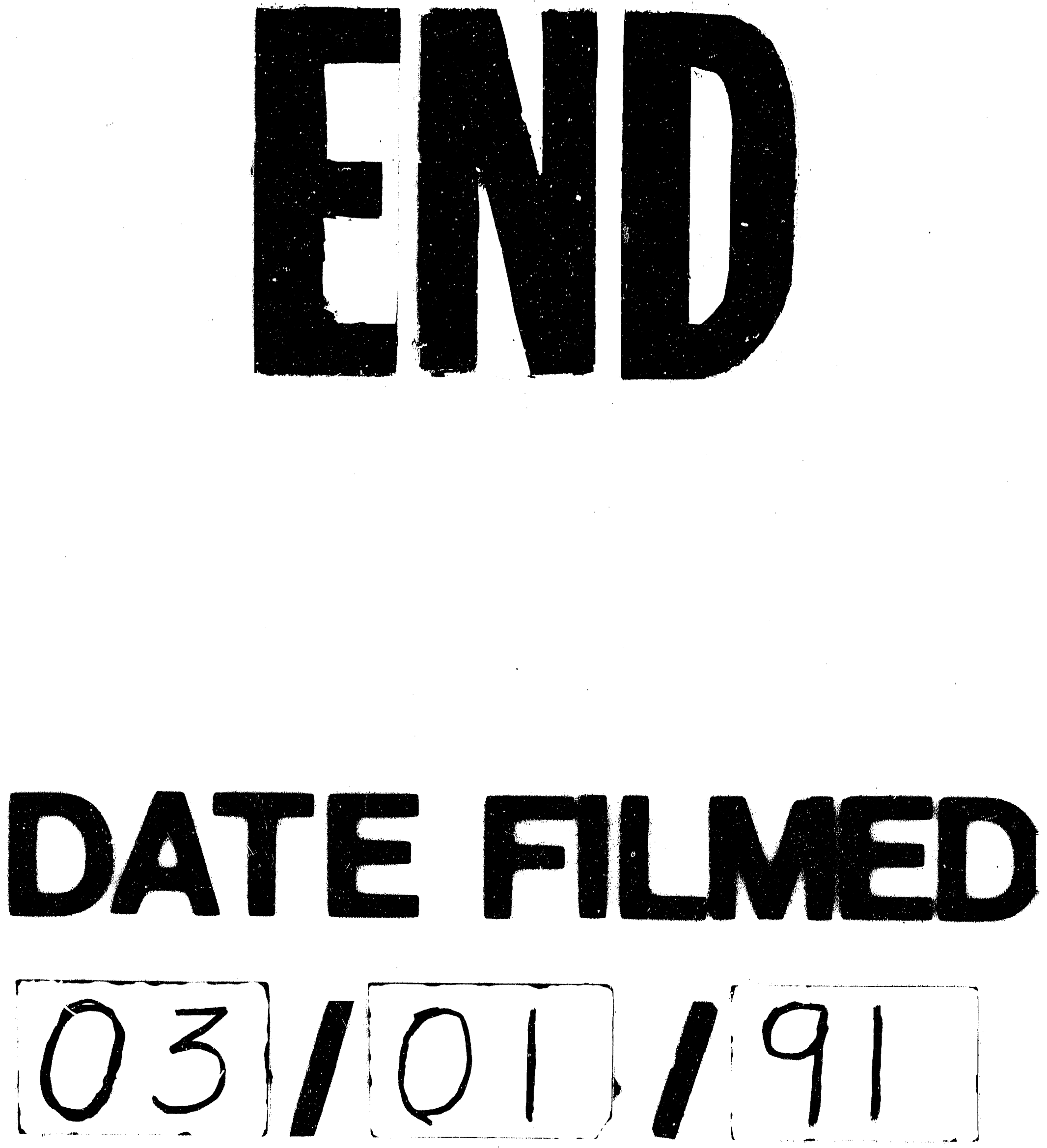
